\title{
On-Line Thermal Barrier Coating Monitoring for Real- Time Failure Protection and Life Maximization
}

\author{
Semi-Annual Technical Progress Report \\ Reporting Period Start Date: October 1, 2002 \\ Reporting Period End Date: March 31, 2003
}

Prepared for:

U.S Department of Energy

National Energy Technology Laboratory

P.O. Box 10940

Pittsburgh, PA 15236-0940

Cooperative Agreement No. DE-FC26-01NT41232

Prepared by:

Dennis H. LeMieux

Siemens Westinghouse Power Corporation 4400 Alafaya Trail

Orlando, Florida 32826

April 2003

Revised 7/1/03 


\section{Disclaimer}

This report is an account of work sponsored by an agency of the United States Government. Neither the United States Government nor any agency thereof, nor any of their employees, nor Siemens Westinghouse Power Corporation make any warranty, express or implied, or assumes any legal liability or responsibility for the accuracy, completeness, or legal fullness of any information, apparatus, product, or process disclosed, or represents that its use would not infringe privately owned rights. Reference, herein, to any specific commercial product, process, or service by trade name, trademark, manufacturer, or otherwise does not necessarily constitute or imply the endorsement, recommendation, or favoring by the United States Government or any agency thereof. The views and opinions of authors expressed herein do not necessarily state or reflect those of the United States Government or any agency thereof. 
$\begin{array}{lll}1.0 & \text { ABSTRACT } & 5\end{array}$

$\begin{array}{lll}2.0 & \text { INTRODUCTION }\end{array}$

$\begin{array}{lll}3.0 & \text { EXECUTIVE SUMMARY } & 7\end{array}$

4.0 TASK 2: DEVELOP ON-LINE TBC MONITOR FOR BLADES 8

4.1 SUBTASK 2.1 - CONDUCT HIGH HEAT FLUX TESTS FOR MONITORING TBC FAILURES 8

4.1.1 Experiment 8 - 9

4.1.2 Results and Discussion $\quad 9-10$

4.1.3 Conclusions 11

4.2 SUBTASK 2.2 - DEVELOP REMAINING LIFE PREDICTION MODEL $\quad 12$

4.2.1 Experiment 12

4.2.2 Results and Discussion 13

4.2.3 Conclusion 13

5.0 TASK 3: DEVELOP ON-LINE TBC MONITOR FOR VANES 14

5.1 Experiment 14

5.2 Results and Discussion $15-16$

6.0 TASK 4: DEVELOP TBC REMAINING LIFE PREDICTION MODEL 16

6.1.1 Experiment - Modifications 16

6.1.2 Results and Discussion 17

$\begin{array}{lll}7.0 & \text { CONCLUSION } & 18\end{array}$

8.0 TECHNICAL MILESTONE UPDATE 18

9.0 PROGRAM STATUS - ACHIEVEMENTS 18

10.0 STATUS OF MILESTONES 18

$\begin{array}{ll}11.0 & \text { MILESTONE COMPLETION, } 2002\end{array}$

12.0 MILESTONE COMPLETION, 2003 


\section{LIST OF TABLES}

Table 1 Detectors employed in the Emissometer

Table 2 Summary of Free Standing 8YSZ Emittance

\section{LIST OF FIGURES}

Figure 1 Christiansen Emittance as a function of Temperature of 8SYZ

Figure 2 Tubular Specimen sample - High Heat Flux Testing

Figure 3 3D Model of On-line monitor viewing direction

Figure 4 Westinghouse High Heat Flux Test Rig 


\section{ON-LINE THERMAL BARRIER COATING MONITORING FOR REAL-TIME FAILURE PROTECTION AND LIFE MAXIMIZATION}

\section{$1.0 \quad$ ABSTRACT}

Under the sponsorship of the U. S. Department of Energy's National Energy Laboratory, Siemens Westinghouse Power Corporation proposes a four year program titled, "On-Line Thermal Barrier Coating (TBC) Monitor for Real-Time Failure Protection and Life Maximization," to develop, build and install the first generation of an on-line TBC monitoring system for use on land-based advanced gas turbines (AGT).

Federal deregulation in electric power generation has accelerated power plant owner's demand for improved reliability, availability, and maintainability (RAM) of the land-based advanced gas turbines. As a result, firing temperatures have been increased substantially in the advanced turbine engines, and the TBCs have been developed for maximum protection and life of all critical engine components operating at these higher temperatures. Losing TBC protection can, therefore, accelerate the degradation of substrate component materials and eventually lead to a premature failure of critical components and costly unscheduled power outages. This program seeks to substantially improve the operating life of high cost gas turbine components using TBC; thereby, lowering the cost of maintenance leading to lower cost of electricity.

Siemens Westinghouse Power Corporation has teamed with Indigo Systems, a supplier of state-of-the-art infrared camera systems, and Wayne State University, a leading research organization in the field of infrared non-destructive examination (NDE), to complete the program. 


\subsection{INTRODUCTION}

The objective of this proposed work is to design, build, and install a gas turbine blade and vane TBC monitor that will monitor, in real time, during turbine operation, the formation and progression of critical TBC defects. The monitor will track and report on the progression of TBC defects, estimate remaining TBC life, and notify operations of impending damage. The program goal is to alleviate unscheduled outages due to TBC failure and engine damage by having a monitor system to assure that irreversible damage does not occur.

The four year program, as managed by Siemens Westinghouse, will begin with a combined effort by our Design Engineering, Materials Engineering, Diagnostics, and Advanced Sensors groups, together with Indigo Systems to develop the conceptual design for the monitor. Blade and Vane monitors, based on our preliminary work, will then be designed and built by Indigo Systems and Siemens Westinghouse's Advanced Sensors group. Although blade and vane monitor tasks will start at the same time, the blade monitor will slightly lead the vane monitor due to the relative maturity of the concept. Once the sensor designs are complete, the advisory system will be designed to incorporate the sensor and TBC remaining life model inputs. Once all systems are built, they will be installed on an engine that is operated by Siemens Westinghouse. The monitor will be operationally tested on a relevant gas turbine engine at a selected site.

The project is defined along six major technical tasks including:

Task 1: Conceptual Design of System Configuration and Definition

Task 2: Develop On-line TBC Monitor for Blades

Task 3: Develop On-line TBC Monitor for Vanes

Task 4: Develop TBC Remaining Life Prediction Model

Task 5: Develop Artificial Intelligence (Al)-based Supervisory System

Task 6: Field Trials

This report summarizes results from these tasks. 


\subsection{EXECUTIVE SUMMARY}

Under the sponsorship of the U. S. Department of Energy's National Energy Laboratory, Siemens Westinghouse Power Corporation proposes a four year program titled, "On-Line Thermal Barrier Coating (TBC) Monitor for Real-Time Failure Protection and Life Maximization," to develop, build and install the first generation of an on-line TBC monitoring system for use on land-based advanced gas turbines (AGT).

Federal deregulation in electric power generation has accelerated power plant owner's demand for improved reliability, availability, and maintainability (RAM) of the land-based advanced gas turbines. As a result, firing temperatures have been increased substantially in the advanced turbine engines, and the TBCs have been developed for maximum protection and life of all critical engine components operating at these higher temperatures. Losing TBC protection can accelerate the degradation of substrate component materials and eventually lead to a premature failure of critical components and costly unscheduled power outages. This program seeks to substantially improve the operating life of high cost gas turbine components using TBC; thereby, lowering the cost of maintenance leading to lower cost of electricity.

Siemens Westinghouse Power Corporation has teamed with Indigo Systems; a supplier of state-of-the-art infrared camera systems, and Wayne State University, a leading research organization in the field of infrared non-destructive examination (NDE), to complete the program.

The anticipated benefits are listed below:

(1) Use of the on-line TBC monitor will significantly improve plant reliability and availability by extending critical component lives. Damaged TBC can be identified early and repaired before the component's catastrophic failure.

(2) Use of the on-line TBC monitor will significantly increase availability of peaking gas turbines by eliminating down time required for frequent borescope examination of TBC's.

(3) The on-line TBC monitor can be used on all existing and new gas turbines that use TBC to protect critical turbine parts. The fundamental concepts of the on-line TBC monitoring is equally applicable to smaller land, aero and marine based gas turbines. This opens future global market opportunities for the team to pursue.

(4) The financial payback of this technology comes in the form of reduced maintenance costs and having power plants available when they would not have been. All of today's advanced gas turbines can benefit from this monitor. We expect over 600 "F" and " $G$ " class gas turbines to be in service over the next 12 years. The total estimated 12 -year life-cycle maintenance cost savings for these $600+$ units is expected to be over $\$ 600 \mathrm{M}$. 


\subsection{TASK 2: DEVELOP ON-LINE TBC MONITOR FOR BLADES}

\section{PROGRAM PROPOSAL}

\subsection{SUBTASK 2.1 DETERMINE TEMPERATURE-DEPENDENT IR CHARACTERISTICS OF BLADE SURFACE AND GT WORKING FLUID}

2.1.1 Measure Spectroscope Properties of GT Working Fluid: Infrared transmission, absorption, and emissivity properties of the turbine engine atmosphere will be determined within the range of operating parameters expected. The high-pressure, high-temperature, high-velocity gas will effect the relationship between radiance and temperature as will the TBC damage.

2.1.2 Measure TBC Coated Blade Emissions as Function of Temperature: Thermal emission characteristics will be determined for several states of the TBC condition. They will include sintering, contamination and defect formation. Characteristics of deteriorating TBCs will be studied. Deteriorating TBC emissions will demonstrate a local step change in emissivity.

2.1.3 Characterize Emissions from TBC Defects (APS): Emissions from critical TBC defects types will be determined. Debond growth and surface temperature changes will influence the radiance and radiant transients. The debond is expected to cause an increase in the absolute temperature of the TBC surface. As the same debond grows, the temperature will increase and the imaged region of the spallation will grow. Basic measurement capabilities will be investigated by building a laboratory model of the TBC blade sensor.

\subsubsection{EXPERIMENTS}

Ceramic TBCs are used on metal turbine blades and engines to operate at higher temperatures to increase power, improve fuel consumption, and lower emissions into the environment. However, studies have shown that ceramics which show promise as TBCs have low, variable emittance and significant reflectance and transmittance at short wavelengths, which leads to increased uncertainties of measurement for short-wave infrared. Combustion reflection off the TBC and optical penetration through the TBC are significant.

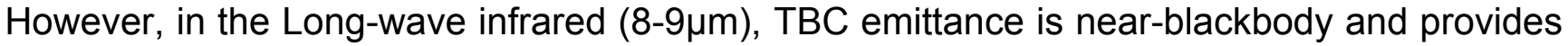
for the measurement of radiation at the surface with minimal penetration.

The radiative properties of the TBC samples were measured by Advance Fuel Research (AFR) with a Benchtop Emissometer. Samples placed in the Emissometer were irradiated from all directions by energy from a near-blackbody source, and reflected and transmitted energies collected at directional near-normal take-off angles with an FTIR spectrometer. Thus, spectral hemispherical-directional reflectance and spectral hemispherical-directional transmittance are measured, and conservation of energy (closure) provides the spectral directional emittance $(E=1-R-T)$. A liquid nitrogen cooled MCT detector was used to measure the 20-1.2 micron spectral region. The detector has low sensitivity as it approaches the 1.2 micron region and this is observed as increased "noise" in plotted data. Torch heating in air 
on the backside of a sample is performed to achieve requested high temperatures for measurement. The strongest absorption band of torch generated carbon dioxide gas at $\sim 4.1$ microns presents itself as a fairly narrow band interference in the spectral data. Table 1 indicates the types of detectors employed and their ranges.

Table 1 - Detectors employed in the Emissometer

\begin{tabular}{|l|c|}
\hline \multicolumn{1}{|c|}{ Detector } & Spectral Range \\
\hline $\begin{array}{l}\text { Mercury-Cadmium-Telluride } \\
\text { (MCT) (liquid nitrogen cooled) }\end{array}$ & $500 \mathrm{~cm}^{-1}-8,500 \mathrm{~cm}^{-1}$ or $20 \mu \mathrm{m}-1.18 \mu \mathrm{m}$ \\
\hline $\begin{array}{l}\text { Silicon-Photodiode } \\
\text { (ambient temperature) }\end{array}$ & $8,500 \mathrm{~cm}^{-1}-12,500 \mathrm{~cm}^{-1}$ or $1.18 \mu \mathrm{m}-0.8 \mu \mathrm{m}$ \\
\hline
\end{tabular}

In order to collect data over the wide spectral range at a specific temperature, measurements were taken sequentially for both detectors while maintaining a constant temperature on the surface.

\section{Sample Preparation}

Test samples of free standing 8YSZ on a graphite substrate were supplied to Advance Fuel Research for measurements of spectral emittance. The temperatures requested were $1000 \mathrm{C}$, $1100 \mathrm{C}, 1200 \mathrm{C}, 1300 \mathrm{C}$, and $1400 \mathrm{C}$. The temperature range was achieved by heating the back surface with an oxy-acetylene torch.

\subsubsection{RESULTS AND DISCUSSION}

Results for this test are for clean TBC surfaces and measured at wavelengths nominally from $1.1 \mu \mathrm{m}-14 \mu \mathrm{m}$. The results of the data has concluded that emissions from Near Infrared and Mid Infrared exhibit low emittance and high emittance in the Long wave Infrared. Additional laboratory experiments are being performed to measure the thermal contrast during the progression of defect formation. Preliminary results have profiled the maximization thermal contrast for defect detection with an infrared focal plane array detector at $1550 \mathrm{~nm}$. Further experiments will profile these contrast measurements in test results from data at the Westinghouse Plasma Center and will be reported in the next reporting period. The results of the emittance measurements of clean TBC are summarized in Table 2 and Figure 1.

Table 2 - Summary of Emittance

\begin{tabular}{|c|c|c|c|c|c|c|}
\hline Sample - 8SYZ & $\begin{array}{l}\text { 1000C } \\
\text { initial }\end{array}$ & $1100 \mathrm{C}$ & $1200 \mathrm{C}$ & 1300C & $1400 \mathrm{C}$ & $\begin{array}{r}1000 C \\
\text { final }\end{array}$ \\
\hline \multicolumn{7}{|c|}{ Near Infrared $\mathbf{. 9 - 1 , 6 5 \mu m}$} \\
\hline 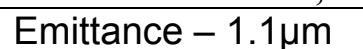 & 0.12 & 0.11 & 0.14 & 0.18 & 0.22 & 0.08 \\
\hline Emittance $-1.2 \mu \mathrm{m}$ & 0.09 & 0.10 & 0.15 & 0.18 & 0.22 & 0.08 \\
\hline Emittance $-1.3 \mu \mathrm{m}$ & 0.12 & 0.12 & 0.15 & 0.18 & 0.22 & 0.09 \\
\hline Emittance $-1.4 \mu \mathrm{m}$ & 0.11 & 0.10 & 0.14 & 0.17 & 0.21 & 0.07 \\
\hline Emittance $-1.5 \mu \mathrm{m}$ & 0.11 & 0.11 & 0.14 & 0.18 & 0.22 & 0.09 \\
\hline 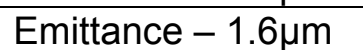 & 0.12 & 0.12 & 0.15 & 0.18 & 0.22 & 0.10 \\
\hline Emittance - 1.65 $\mu \mathrm{m}$ & 0.12 & 0.11 & 0.14 & 0.18 & 0.22 & 0.09 \\
\hline
\end{tabular}




\begin{tabular}{|c|c|c|c|c|c|c|}
\hline Sample - 8SYZ & $\begin{array}{l}\text { 1000C } \\
\text { initial }\end{array}$ & $1100 \mathrm{C}$ & $1200 \mathrm{C}$ & $1300 \mathrm{C}$ & $1400 \mathrm{C}$ & $\begin{array}{r}1000 \mathrm{C} \\
\text { final }\end{array}$ \\
\hline \multicolumn{7}{|l|}{ Mid Infrared 3-5 $\mu \mathrm{m}$} \\
\hline 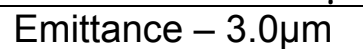 & 0.13 & 0.12 & 0.15 & 0.18 & 0.22 & 0.10 \\
\hline Emittance $-3.5 \mu \mathrm{m}$ & 0.13 & 0.12 & 0.16 & 0.19 & 0.23 & 0.10 \\
\hline Emittance - 4.0um & 0.18 & 0.18 & 0.21 & 0.24 & 0.27 & 0.17 \\
\hline Emittance $-4.5 \mu \mathrm{m}$ & 0.31 & 0.32 & 0.34 & 0.37 & 0.39 & 0.30 \\
\hline Emittance $-5.0 \mu \mathrm{m}$ & 0.47 & 0.48 & 0.50 & 0.52 & 0.54 & 0.47 \\
\hline
\end{tabular}

\begin{tabular}{|c|c|c|c|c|c|c|}
\hline Sample-8SYZ & $\begin{array}{l}1000 \mathrm{C} \\
\text { initial }\end{array}$ & $1100 \mathrm{C}$ & $1200 \mathrm{C}$ & $1300 \mathrm{C}$ & $1400 \mathrm{C}$ & $\begin{array}{r}1000 C \\
\text { final }\end{array}$ \\
\hline \multicolumn{7}{|l|}{ Long Infrared 3-5 $\mu \mathrm{m}$} \\
\hline Emittance $-8.0 \mu \mathrm{m}$ & 0.96 & 0.96 & 0.96 & 0.96 & 0.97 & 0.96 \\
\hline Emittance $-8.5 \mu \mathrm{m}$ & 0.97 & 0.97 & 0.97 & 0.98 & 0.98 & 0.97 \\
\hline Emittance $-9.0 \mu \mathrm{m}$ & 0.98 & 0.98 & 0.98 & 0.98 & 0.98 & 0.98 \\
\hline Emittance $-9.5 \mu \mathrm{m}$ & 0.98 & 0.98 & 0.98 & 0.98 & 0.98 & 0.98 \\
\hline Emittance - 10.0 $\mu \mathrm{m}$ & 0.99 & 0.99 & 0.99 & 0.99 & 0.99 & 0.99 \\
\hline Emittance $-10.5 \mu \mathrm{m}$ & 0.99 & 0.99 & 0.99 & 1.00 & 1.00 & 0.99 \\
\hline Emittance - 11.0um & 0.99 & 1.00 & 1.00 & 1.00 & 1.00 & 0.99 \\
\hline Emittance $-11.5 \mu \mathrm{m}$ & 0.99 & 0.99 & 0.99 & 1.00 & 1.00 & 0.99 \\
\hline Emittance - 12.0 $\mu \mathrm{m}$ & 1.00 & 0.99 & 1.00 & 1.00 & 1.00 & 1.00 \\
\hline Emittance - 12.5 $\mu \mathrm{m}$ & 0.99 & 0.99 & 0.99 & 0.99 & 0.99 & 0.99 \\
\hline 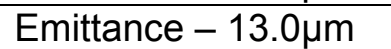 & 0.98 & 0.98 & 0.98 & 0.98 & 0.99 & 0.98 \\
\hline Emittance $-13.5 \mu \mathrm{m}$ & 0.96 & 0.96 & 0.96 & 0.96 & 0.97 & 0.96 \\
\hline Emittance $-14.0 \mu \mathrm{m}$ & 0.91 & 0.91 & 0.92 & 0.92 & 0.93 & 0.91 \\
\hline
\end{tabular}

Christiansen Emittance as a Function of Temperature for Sample \#D0

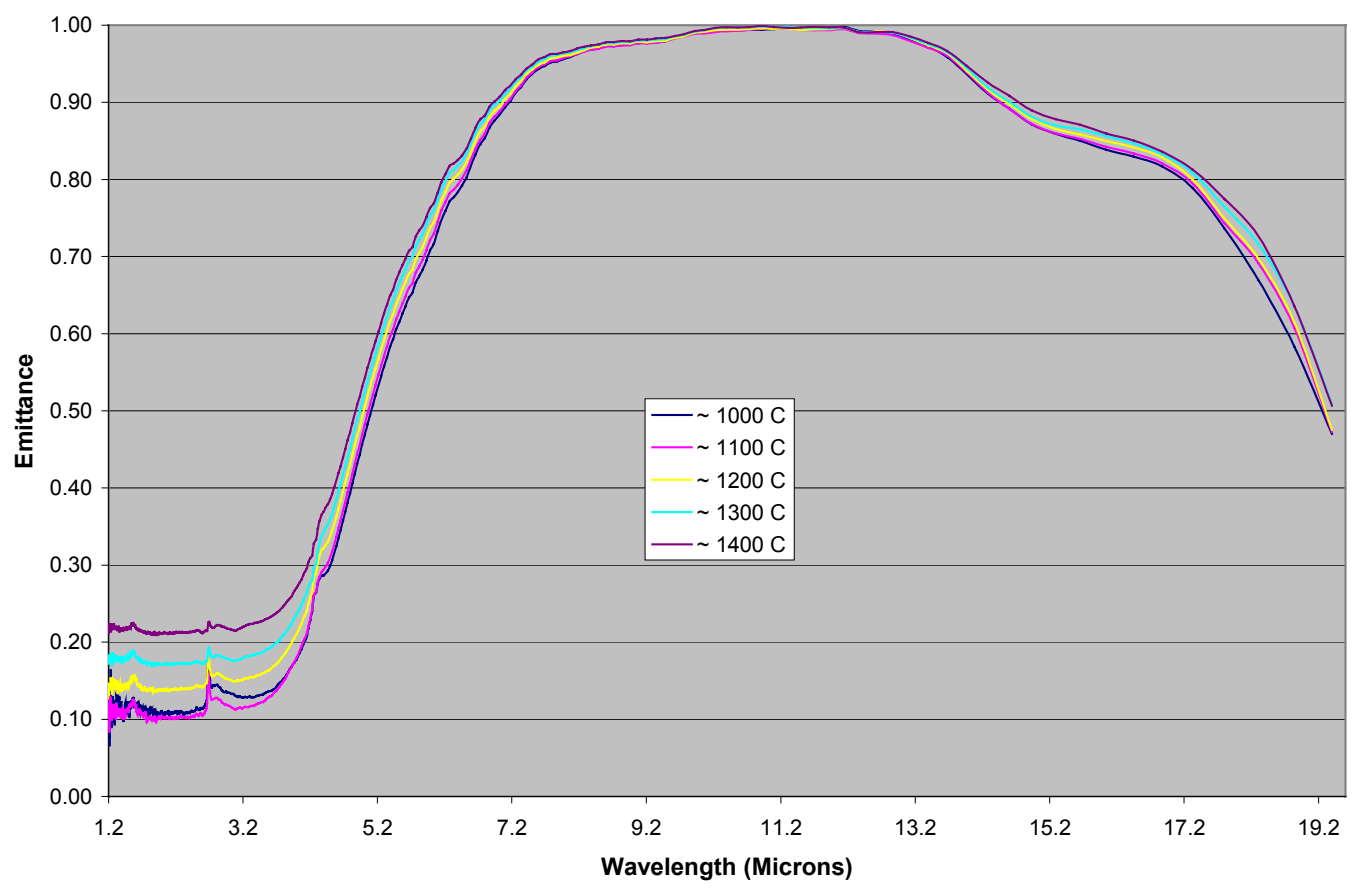

Figure 1 


\subsubsection{CONCLUSIONS}

Testing conducted at Advance Fuel Research and the Westinghouse Plasma Facility has demonstrated that air plasma sprayed (APS) ceramic TBC have low, variable emittance and significant reflectance and transmittance at short wavelengths. A design of experiments established these wavelengths and their influence on TBC spallation. These experiments will resolve several types of defect caused by the following categories; temperatures, foreign object damage (FOD) or manufacturing process damage.

This design of experiments will also broaden the program scope, by not only being able to identify defects after they occur, but will investigate various defect characteristics of TBC coated specimens for the detection of pre-spallation events. The following data profiles the temperature of a 600-micron thickness APS thermal barrier coated tubular test specimen (Figure 2). The infrared image (IR Image 1) profiles one of many infrared images that demonstrate the ability of an infrared imaging system with a spectral response of 3-5 microns to detect a $1 / 4 "$ defect in APS thermal barrier coating. The following test specimens were inserted into the High Heat Flux Test Rig (HHFTR) where the test specimen rotates at 500$\mathrm{rpm}$. Hydrogen and argon plasma torch heating provides a surface temperature of $\sim 2550 \mathrm{~F}$ and mid wall temperature of $\sim 1550 \mathrm{~F}$. The mid wall temperature is maintained through the hollow tubular specimens by cool air through the specimen.

\section{Westinghouse Plasma Facility High Heat Flux Testing}

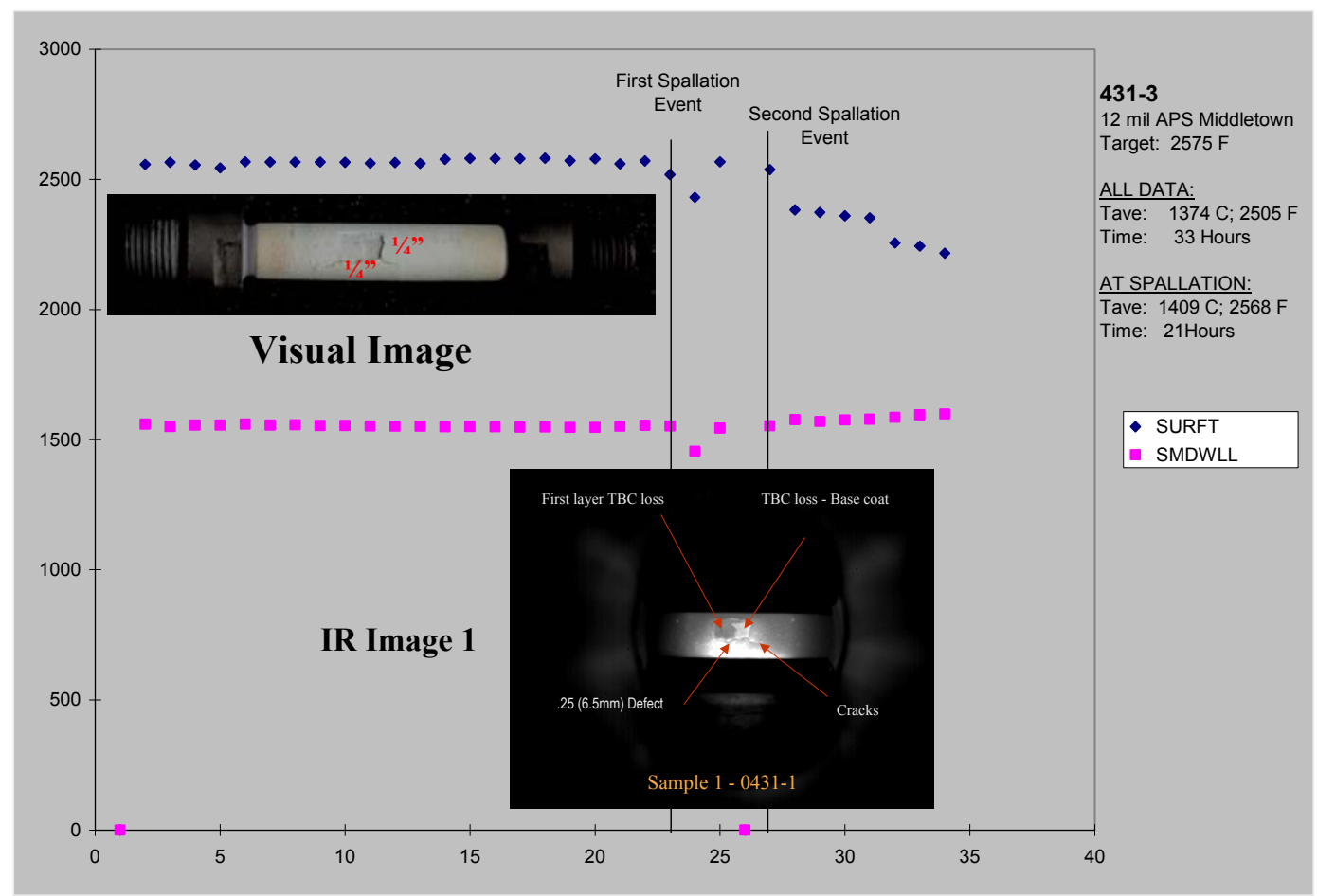

Figure 2 


\subsection{SUBTASK 2.2 DEVELOP IR MONITOR FOR TBC COATED BLADES}

This subtask consists of the following components: (1) select/develop IR sensors; (2) determine data types, transmission rate, and formats, (3) design data analysis scheme for the GT-TBC monitor inputs, (4) determine control interface and blade sensor attachment, and (5) develop blade surface condition monitor.

The array detector will be a state-of-the-art, cooled, solid state, infrared detector. Work conducted in Task 1 shall determine the best combination of atmospheric spectral window and maximum TBC system information. Once determined, the detectors will be designed within these spectral windows. The detector spectral selection used for embodiment 2 shall have the additional consideration of fiber optic transport. The fiber optic system must be rugged in the AGT environment and allow remote detector location outside of the AGT enclosure, if possible. The fiber optic device shall be designed to allow replacement of the fiber bundles, including gas-exposed viewing optics without disassembling any AGT components. The closest location for detector installation is outside of the shell of the turbine.

Future embodiments may allow complete gas path viewing fiber and detector replacement without shutting the turbine down, an internally installed optical directly involved in this activity. Design Engineering will determine the optimum sensor vantagepoints with the following considerations: pressure boundary control, serviceability, viewing optics protection, critical region viewing, viewing regions, and sensor installation minimization. This activity will establish guidelines and limitations for sensor type, placement and attachment. The Program Manager along with SWPC Design Engineering will publish an installation requirement complete with specifications, attachment requirements, and modified and approved AGT drawings demonstrating penetrations and detailed pressure boundaries. They will be responsible for approving all sensor attachments and installation procedures.

\subsubsection{Experiments}

The intent is to develop a system for real-time viewing and, recording of a Thermal Barrier Coated gas turbine component experiencing the onset of TBC spallation. The overall program involves continuously viewing a row 1-turbine blade surface via an infrared camera system. Figure 3 profiles the viewing layout.

Engineering have completed drawing layouts and design reviews with the intent of viewing both internal path and any potential obstructions and interference's external to the engine casing such as piping, brackets and other features. These drawings have clear view of row 1 blades from a radial oblique viewing direction. The following figure profiles the viewing direction and penetration locations into the gas turbine generator.

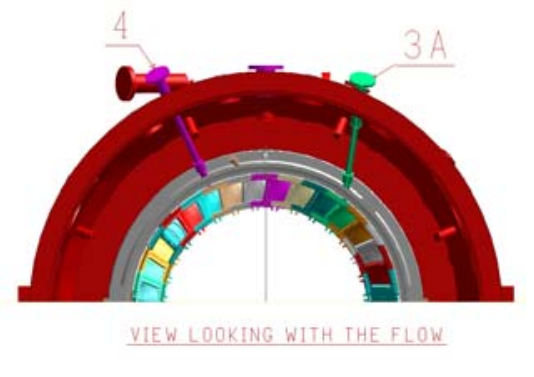

Figure 3 


\subsubsection{RESULTS AND DISCUSSION}

The conceptual design will allow the implementation of the concept to more thoroughly assess practical issues of the sensors implementation and cost. Along with the conceptual design, some additional verification tests or analysis will be performed on the concept to allow a better assessment of the monitoring system. Dual high-speed infrared cameras will operate with a spectral response of $0.9-1.65 \mu \mathrm{m}$ and $3-5 \mu \mathrm{m}$ and integration or shutter speed on the order of 3 microseconds. These cameras with a blade position sensor will allow viewing of a single blade surfaces during engine operation. Both systems have state-of-theart real-time infrared (IR) sensors that captures images on the blades rotating at 3600rpm which is equivalent to $400 \mathrm{~m} / \mathrm{s}$ linear speed.

\subsubsection{CONCLUSSION}

Currently, to date, the program task objectives have identified the emittance of clean 8SYZ air plasma sprayed (APS) TBC. The results of the emissivity measurements demonstrate a broad variation of the level of total emissivity. Temperature measurements would be more accurate in the long wavelength infrared (LWIR) where ceramic TBC emissivities are typically high and stable. Clean TBC in Gas turbine engine have demonstrated low, variable emissivities at short wavelengths, which could lead to serious temperature measurement inaccuracies. As the laboratory tests continue, a clearer picture is emerging in regard to the defect contrast characteristics of thermal barrier coatings (TBC) for both cameras. Further testing has confirmed that the maximum peak contrast for defect detection occurs in the Near Infrared $(0.9-1.65 \mu \mathrm{m})$. This data and results will be reported in the next reporting period. 


\subsection{TASK 3: DEVELOP ON-LINE TBC MONITOR FOR VANES}

\section{Program Proposal}

The objectives for Row 1 TBC vane coating monitor is to detect TBC coating degradation of the hottest location in the expander, and to provide an early warning for degradation of TBC coating in the hot gas path. Monitoring information from the Row 1 vane will also be integrated into TBC lifing models to allow outage planning and maximization of availability. In order for the Row 1 Vane monitor to meet these objectives, it will need to have the following criteria:

- The monitoring system should be capable of providing real-time data, and the sensors should have life capability in excess of normal outage times at operating conditions.

- The monitor will need to be an early indication of TBC coating condition changes.

- The monitor will need to monitor the vane globally so that deterioration of particular areas of the vane will be detected.

- The distribution of sensors must be minimized to avoid installation and operational complication.

- The monitor will need to be sensitive to subtle changes in TBC coating conditions.

- Preferably the monitor should be dependent on sensing the condition of the TBC, regardless of the cause of the deterioration. Detection of foreign object damage, as well as temperature damage, will be important.

There are no current sensors that meet all of the above criteria. Mature techniques for sensing (e.g., thermocouples) can be used to locally detect Row 1 vane problems, at least after the problem advances to the point where damage has occurred in the TBC coating and the vane. This program will evaluate some emerging technologies for potential application to this problem. At the same time, mature technologies will be used as a back up in the testing, serving to baseline the interpretation of the TBC coating life sensing system. The result of the program will be the development of a vane TBC coating life detection system that incorporates the state-of-the art methods of detecting coating failures.

\subsection{EXPERIMENTS}

Plans for Second Level Down Selection

Based on the six desired objectives for the vane sensor, we have reduced the candidates under investigation from the initial ten, to the most likely five. These down selected candidates were described and reported in previous reporting period. The conceptual design will allow the implementation of each concept to more thoroughly assess practical issues of the sensors implementation and cost. Along with the conceptual design, some additional verification tests or analysis will be performed on each sensor concept to allow a better assessment of the sensor's promise. The following sensor has been chosen for most likely success for vane monitoring. 


\subsection{RESULTS AND DISCUSSION}

\section{Selected Sensor: Acoustic Waveguide (AWG)}

\section{Status of Preliminary Testing:}

1. Laboratory tests indicate that an AWG can launch slow $(1900 \mathrm{~m} / \mathrm{sec})$ moving surface waves through thermal barrier coatings (TBC) and the coating considerably damps (reduces the signal level) of the transmitted wave. In an experiment with $10 \mathrm{~cm} \times 15 \mathrm{~cm}$ Hastelloy $X$ plates, one of bare metal, and one coated with a 20 mil thick layer of air plasma sprayed (APS) TBC, the coating reduced the transmitted signal level by 10 times. This should be helpful when AWG are used for interrogating the condition of gas turbine vanes and parts.

2. Field tests carried out on a "V" machine in Berlin demonstrated that an acoustic signal could be transmitted via an AWG about 2 meters inside a machine, pass through a vane, and be returned via another AWG to be measured outside the machine. The return signal was characteristic of laboratory measurements and therefore we believe capable of providing real-time condition data when the technique is properly refined. Also, after several test runs of the machine, the AWG was still intact.

Planned Tests Status: Laboratory tests are examining specimens with varying amounts of TBC to determine expected signal responses to simulated vane TBC flaws.

\section{Thermal Barrier Coating Acoustic Damping}

As the laboratory tests continue a clearer picture is emerging in regard to the acoustic characteristics of thermal barrier coatings (TBC). Further testing has confirmed that an air plasma sprayed TBC will damp (10 to 1) acoustic surface waves, but only under impact (or FOD type conditions) and with the acoustic waveguide used in receive or listening mode. This damping does not apply under transmit/receive conditions as reported earlier from preliminary tests, but will be present due to pressure pulses generated as blades pass vanes.

\section{Response of Thermal Barrier Coating to Simulated Vane Flaws}

Tests are now underway using $10 \mathrm{~cm} \times 15 \mathrm{~cm}$ Haynes 230 (NiCrAlloy) plates of bare metal, one with a 20mil thick layer of air plasma sprayed (APS) TBC, and other TBC plates with one centimeter wide slots cut in the TBC to simulate spalling. Preliminary results using the AWG sensors in the transmit/receive mode indicate that the TBC transmits much larger (5 to 1) levels than bare metal. Also, the transmitted signal level changes considerably (5 to 1 ) as the number of slots in the TBC increases from one to five. Although all aspects of the acoustic surface wave transmission are not fully understood as yet, it does appear that TBC spalling (simulated by slots) should be detectable.

\section{Acoustic Isolation of AWG Inside Gas Turbine Engine}

With the "V" engine, a 6mm-diameter stainless steel capillary tube was tack welded at various locations within the engine (from the exit to a vane location). The AWG was inserted within the tubing for protection and acoustic isolation. This system performed well, and even though the AWG touched the tube wall at various locations, the acoustic isolation from the 
capillary tubing to AWG, was around 100 to 1 . This design is being used for the FD engine but for certain vane locations, $4 \mathrm{~mm}$-diameter capillary tubing was required. Laboratory tests were performed with the AWG within both $4 \mathrm{~mm}$ and $3 \mathrm{~mm}$ diameter capillary tubing (the AWG diameter is $1 \mathrm{~mm}$ ). It was found that the acoustic isolation for the $4 \mathrm{~mm}$ tubing was 10 to 1 (acceptable for the FD tests) while the $3 \mathrm{~mm}$ tubing had little acoustic isolation.

\subsection{TASK 4: DEVELOP TBC REMAINING LIFE PREDICTION MODEL}

\section{PROGRAM PROPOSAL}

The objectives of task 4 are (1) monitor failure progression of TBC's under high heat flux conditions (Subtasks 4.1) and (2) develop a numerical model to describe the failure progression as a function of the loading regime (Subtask 4.2).

\subsection{SUBTASK 4.1 CONDUCT HIGH HEAT FLUX TESTS FOR MONITORING TBC FAILURES}

The high heat flux testing rig (HHFTR) at Westinghouse Plasma Corporation (WPC), Madison, PA will be upgraded to allow monitoring of failure progression under engine-like temperature conditions. The NDE monitoring device proposed in the program to evaluate TBC reliability during engine service will be incorporated on a sub-scale level into the test chamber of the available test rig. WPC has a unique world-class facility for testing coated samples in a thermal fatigue-thermal gradient.

A tubular specimen with APS thermal barrier coating is subjected to the high heat flux with active cooling. A uniform surface temperature of $>1350^{\circ} \mathrm{C}$ will be maintained at the thermal barrier coating outer surface. A large temperature gradient across the TBC layer will be created such that the TBC-to metal interface temperature is held at $<1000^{\circ} \mathrm{C}$ while the outer surface is at the high temperature mentioned above. A cyclic operation with heating cycle duration's of 3 minutes to $>8$ hours can be achieved.

The monitoring device will capture the TBC failure progression during testing period. Thereby, it is able to detect and quantify delamination as well as vertical crack growth.

\subsubsection{MODIFICATION OF CURRENT HIGH HEAT FLUX TEST RIG:}

The test chamber and the data acquisition system of the High Heat Flux Test Rig (HHFTR) was modified to monitor the specimen condition during high heat flux testing. A test chamber was designed and manufactured such that NDE devices can easily monitor the rotating test specimen. Image analysis software is currently being developed by Siemens CT Technologies in Princeton, New Jersey and will be incorporated into the data acquisition system to obtain results of the failure progression.

The modification of the high heat flux test rig, during this task, consisted of a new chamber design and view sights for both an Indigo Infrared Camera with a spectral response of 0.91.65 microns and a Land Optical Pyrometer with a spectral response at 9.0 micron. Figure 4 are images of the High Heat Flux Test Rig after modifications and an example of a sample failure during the course of a test sequence in Figure 5. 
The following test sequence is used to evaluate and quantify the new chamber for the modify HHFTR.

- Load Sample

- Input specimen ID cycle parameters through the test rig user interface

- Set heat source power level to obtain the appropriate surface temperature

- Set substrate coolant flow rate and/or temperature to obtain the desired bond coat temperature as determined from the embedded thermocouple

- Switch system to automatic thermal cycle load

- Configure system and Pyrometer to sample surface temperature during sample failure

- Synchronize infrared camera with test specimen and acquire radiance data during sample failure

Significant Accomplishments:

- Modification and Designs - Design and modification complete for testing and measuring with:

1 Land Pyrometer, spectral response of 9.0 microns

2 Indigo Infrared Focal Plane Array Cameras (spectral response 0.9-1.65 $\mu \mathrm{m}$ and 3.0-5.0 $\mathrm{mm}$ )

6.1.2 RESULTS - Field test data was acquired at a Waltz Mill Plasma Facility. These tests established proof-of-concept for On-line TBC monitoring program. Testing at Waltz Mill facility was very successful.

This task continues analyzing the data for the development of the Remaining Life Prediction Model with more results in the next technical reporting period.

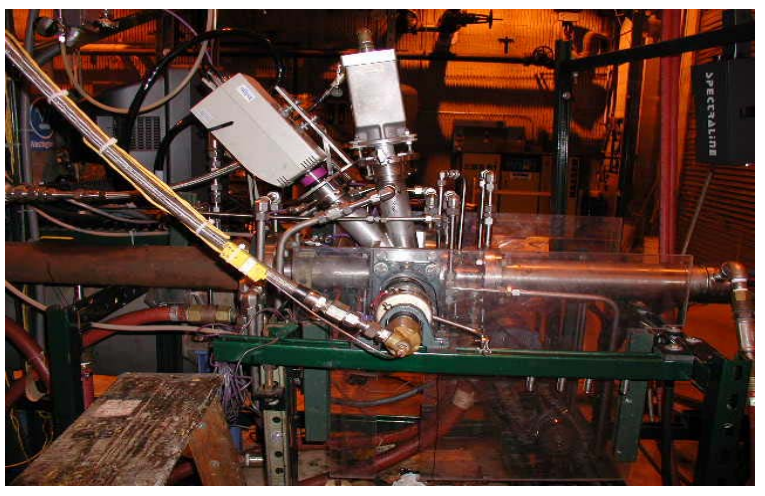

Figure 4-Modified HHFTR

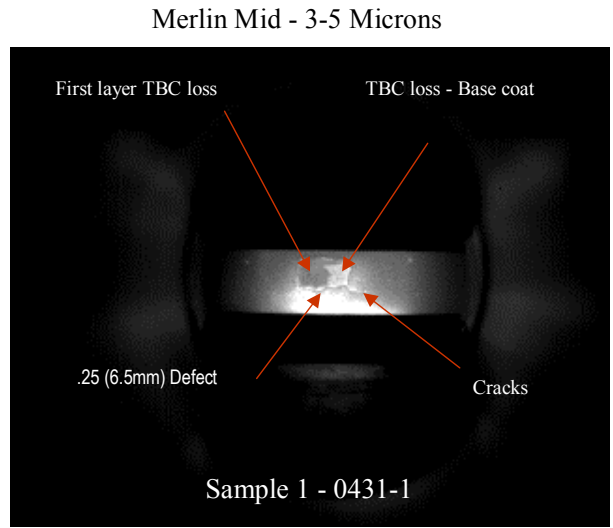

Figure 5-Failed specimen sample 


\subsection{CONCLUSION}

The On-line TBC monitoring program has taken an aggressive approach to develop and install a real-time monitor for both blades and vanes. The program continues to meet and/or exceed the milestone and budgetary requirements. As reported, Siemens Westinghouse engineers have detailed a procedure to penetrate and install a spectral relay-imaging instrument to measurement the radiance, in real-time, row 1 blades. The radiance is relayed through the imaging tube and onto the focal plane array of the high-speed infrared camera operating with a spectral response of $.9-5.0$ microns. The emittance of clean TBC in the short infrared is very reflective, with longer infrared near black body emittance. The contrast in short wave provides the greatest contrast between the TBC coating and bond coat interface. This contrast provides radiance change information to monitor the progressive growth and spallation between these two interfaces. Additional tests next quarter (YR04) will determine the remaining life probability for the On-line numerical model. The On-line TBC Vane Monitor continues with the final down-selection, thus being the Acoustic Wave-Guides. Tests have indicated this sensor can be installed with minimal sensors and wires, very sensitive to TBC loss, and independent of geometry.

The design and assembly of the blade monitoring system will allow viewing of row 1 blades from a radial oblique viewing direction. The monitoring systems will be installed during (Phase 1) in a Westinghouse 501FD engine in Berlin FY03 and (Phase 2) long term LTP host site FY04 yet to be determined.

\subsection{KEY MILESTONE UPDATE}

Current program milestones are on or ahead of schedule.

\subsection{PROGRAM STATUS}

Achievements from 10/01/01 - 03/30/03

- DOW Proof-of-Concept Testing, November 2001

- 3D Model Scoping penetration location and direction, 3 of 4 models complete

- Westinghouse Plasma Center HHFTR Modification, Completion May 2002

- Spectroscopy measurements of GT working fluids, DOW Test, November 2001

- Purchase of NIR Infrared Data Acquisition system and rental agreement of Infrared camera head

- Siemens Westinghouse Power Corporation Program review, Completion March 28, 2002

- Select Infrared Hardware, Milestone completion April 2002

- Siemens Westinghouse Power Corporation Program review, Completion May 28, 2002

- Siemens Westinghouse Power Corporation Program review, Completion September 27, 2002

- R5 Design Review for Radial Penetration, Completion January 2003

\subsection{Status of Milestones}

Current program milestones are on or ahead of schedule. 


\subsection{Milestone Completion, 2002}

- Develop Proof of Concept of Infrared Sensor, Complete 12/10/2001

- Select/Develop infrared sensors - The final selection for the core of the blade monitor, the focal plane array, Complete 3/12/02

- Conduct lab prototype experiments on selected vane sensors - The vane sensor elements and concept will be evaluated in a lab environment, Complete 8/30/2002

- Assess computer controls and software needs - This effort will complete the statement of computer and software needs anticipated to input, update and archive the data generated by both the blade and vane monitors. Complete 8/30/2002

- Modify current high heat flux test rig - The High-Heat Facility rig test will be retrofit for Blade monitor simulation. Complete 6/6/2002

\subsection{Milestone Completion, 2003}

- Characterize emissions from TBC defects (APS)-Infrared emission from TBC and associated progressions of deterioration will be characterized, I.E. debond growth, spall. 